\title{
“English From Zog”: Analisando a Adequação do Livro Didático de Inglês do Programa Acelera Brasil
}

\author{
Patrícia Helena da Silva Costa \\ Universidade Federal do Rio de Janeiro
}

\begin{abstract}
Resumo
Este artigo examina a primeira unidade do livro didático Zip From Zog 5A, utilizado nas aulas de Inglês do Programa Acelera Brasil. A fim de analisarmos a adequação do livro ao Programa, contaremos com Cunningsworth (1995), Tílio \& Rocha (2009) e com os Parâmetros Curriculares Nacionais do Ensino Fundamental (1997).
\end{abstract}

Palavras-chave: livro didático de Inglês, Programa Acelera Brasil, análise de adequação.

\begin{abstract}
This article examines the first unit of the coursebook Zip From Zog 5A used in the English classes of Programa Acelera Brasil. In order to analyze the suitability of the book, we will work with Cunningsworth (1995), Tílio \& Rocha (2009) and the Parâmetros Curriculares do Ensino Fundamental (1997).

Keywords: English coursebook, Programa Acelera Brasil, analysis for suitability.
\end{abstract}

\section{INTRODUÇÃO}

O objetivo deste trabalho é analisar a primeira unidade do livro didático Zip From Zog $5 A$ utilizado nas aulas de Inglês do Programa Acelera Brasil da rede municipal de educação do Rio de Janeiro. Desta forma, pretendemos responder ao seguinte questionamento: em que aspectos o livro didático Zip From Zog se adequa ao Programa Acelera Brasil? A fim de atendermos ao propósito deste trabalho, apresentaremos, a seguir, a estruturação do mesmo.

Na primeira seção, apresentaremos o Programa Acelera Brasil e o emprego do livro didático Zip From Zog nas aulas de Inglês do município do Rio de Janeiro. Na segunda seção, abordaremos o aporte teórico que embasa o presente trabalho. Para tanto, dividiremos esta seção em duas partes: na primeira parte, propiciaremos um diálogo entre 
o Programa Acelera Brasil e os Parâmetros Curriculares Nacionais do Ensino Fundamental (PCN, 1997); já na segunda parte, explicitaremos a análise de adequação proposta por Cunningsworth (1995) e as dimensões da linguagem do livro didático apresentada por Tílio \& Rocha (2009). Na terceira seção, trataremos da análise em si. Por fim, na quarta e última seção, teceremos as considerações finais sobre o trabalho.

\section{CONHECENDO O PROGRAMA ACELERA BRASIL E O LIVRO DIDÁTICO ZIP FROM ZOG}

O Programa Acelera Brasil, iniciado em 1997 pelo Instituto Ayrton Senna em parceria com outros órgãos como o Fundo Nacional de Desenvolvimento da Educação (FNDE/MEC) e a Petrobrás, é um projeto de correção de fluxo escolar com o intuito de eliminar a cultura da repetência nas escolas públicas. O Programa trabalha com alunos multirrepetentes do $2^{\circ}$ ao $4^{\circ}$ anos do Ensino Fundamental, alocados em turmas de 25 alunos e, através de um "tratamento especial” (LALLI, 2000, p. 146), objetiva recuperar a autoestima dos discentes, possibilitando o domínio de conteúdos que permitam que os alunos sejam promovidos ao $6^{\circ}$ ano. Este trabalho direcionado aos alunos do Acelera Brasil inclui a utilização de materiais didáticos elaborados exclusivamente para o público-alvo do programa. Estes materiais, baseados no currículo escolar oficial e que trabalham com as disciplinas básicas, como Português e Matemática, procuram abordar questões que fazem parte do cotidiano dos alunos. Estas matérias básicas são ministradas por um único professor, que pode ser tanto um Professor II, formado em Pedagogia, como um Professor I, formado, por exemplo, em Português. Já as disciplinas de Educação Física, Artes e Língua Estrangeira são regidas por professores formados nestas áreas, respectivamente.

Diferentemente desse material exclusivo aplicado durante as aulas das disciplinas básicas, o livro didático utilizado nas aulas de Inglês faz parte da série Zip From Zog desenvolvida para os alunos integrantes do Programa Rio Criança Global (PRCG). Lançado em outubro de 2009, o PRCG, criado pela Prefeitura do Rio de Janeiro através da Secretaria Municipal de Educação (SME), em parceria com a Sociedade Brasileira de Cultura Inglesa (SBCI), popularmente conhecida como o curso de idiomas Cultura Inglesa, tem como propósito introduzir o ensino de Inglês nas escolas do município, do $1^{\circ}$ 
ao $5^{\circ}$ ano do Ensino Fundamental. Com ênfase na comunicação verbal do idioma, o PRCG objetiva preparar os alunos para que eles possam trabalhar com turismo e interagir com atletas e turistas durante a Copa do Mundo de Futebol de 2014 e os Jogos Olímpicos de 2016.

\section{O PROGRAMA ACELERA BRASIL NO ENSINO FUNDAMENTAL}

Como foi falado anteriormente, um dos objetivos do Programa Acelera Brasil é trabalhar os conteúdos que possibilitem a correção do fluxo escolar dos discentes. Recuperar a autoestima dos alunos através de atividades que abordem o cotidiano juvenil também é uma das metas do Programa.

Neste sentido, o Programa dialoga com os Parâmetros Curriculares Nacionais do Ensino Fundamental (PCN, 1997), já que este discute a relação do ensino com os contextos sociais nos quais os alunos estão inseridos.

O ensino de qualidade que a sociedade demanda atualmente expressa-se aqui como a possibilidade de o sistema educacional vir a propor uma prática educativa adequada às necessidades sociais, políticas, econômicas e culturais da realidade brasileira, que considere os interesses e as motivações dos alunos e garanta as aprendizagens essenciais para a formação de cidadãos autônomos, críticos e participativos, capazes de atuar com competência, dignidade e responsabilidade na sociedade em que vivem. (BRASIL, 1997, p. 27)

Ao pensar o ensino de forma contextualizada, o Programa contribui para o engajamento dos alunos no processo de aprendizagem. Oportunizar a participação dos discentes na construção do conhecimento possibilita uma prática pedagógica baseada no desenvolvimento da autonomia dos mesmos. Devido à relevância que a promoção da autonomia apresenta para o Programa, cabe aqui mencionarmos a sua definição, de acordo com os PCN (1997): "uma opção metodológica que considera a atuação do aluno na construção de seus próprios conhecimentos, valoriza suas experiências, seus conhecimentos prévios e a interação professor-aluno e aluno-aluno" (BRASIL, 1997, p. $61)$.

O documento afirma que, "apresenta-se para a escola, hoje mais do que nunca, a necessidade de assumir-se como espaço social de construção dos significados éticos necessários e constitutivos de toda e qualquer ação de cidadania" (BRASIL, 1997, p. 27). 
Há temas urgentes diretamente ligados ao exercício da cidadania que não podem ser negligenciados pela sala de aula. Como exemplo, os parâmetros citam a violência, a saúde e questões ambientais. Parte-se do princípio de que se os contextos sociais dos alunos são diversos, também os são as questões sociais e os posicionamentos existentes nestas diferentes realidades. Sendo assim, tais problemáticas precisam ser trazidas para a aprendizagem e reflexão dos alunos. Como uma forma de incluir estas discussões no currículo, o documento apresenta os Temas Transversais Ética, Meio Ambiente, Pluralidade Cultural, Saúde e Orientação Sexual. A proposta é que estes temas perpassem as disciplinas escolares, de forma a articulá-los aos conhecimentos específicos de cada área do conhecimento.

Cabe ressaltar aqui o papel norteador dos parâmetros. Ao sugerir uma prática pedagógica situada e em constante diálogo com as realidades sociais dos alunos, os PCNs (1997) não se configuram como uma receita a ser seguida, mas sim, como orientações que possam embasar o trabalho docente.

\section{UMA PROPOSTA DE ANÁLISE DO LIVRO DIDÁTICO}

Segundo os PCNs (1997) "o livro didático é um material de forte influência na prática de ensino brasileira. É preciso que os professores estejam atentos à qualidade, à coerência e a eventuais restrições que apresentem em relação aos objetivos educacionais propostos". (BRASIL, 1997, p. 67). Trazendo essa questão para o Programa Acelera Brasil, podemos dizer que se o material didático utilizado pelos professores regentes foi pensado com o intuito de atender aos objetivos do Programa, o ideal é que a mesma preocupação seja estendida ao livro didático de Inglês.

Como forma de pôr em prática a reflexão apontada pelos Parâmetros, contaremos com Cunningsworth (1995) e sua análise de adequação. Para o autor, "os livros didáticos devem auxiliar os aprendizes a empregar o idioma efetivamente, em contextos reais de uso, através da utilização de materiais autênticos ${ }^{1}$, criando situações realistas e encorajando os alunos a participarem em atividades que ajudem a desenvolver

\footnotetext{
${ }^{1}$ Entendo materiais autênticos como aqueles que remetem a uma experiência da realidade, e que por isso, demonstram o comportamento de língua real, em contraposição a uma amostra de língua artificial. (WIDDOWSON, 1979, apud, VIGIA-DIAS \& SILVA, 1998).
} 
habilidades e estratégias comunicativas" (CUNNINGSWORTH, 1995, p. 25)². Além disso, o autor acredita que, considerando a utilidade e a relevância da língua alvo para os alunos, faz-se necessário, também, olharmos com detalhe para os itens linguísticos que são apresentados no livro didático.

Ao retomarmos o seguinte trecho dos PCNs (1997, p. 27) no qual "apresenta-se para a escola, hoje mais do que nunca, a necessidade de assumir-se como espaço social de construção dos significados éticos necessários e constitutivos de toda e qualquer ação de cidadania", percebemos as instituições de ensino inseridas em um momento contemporâneo que demanda indivíduos participativos na construção de sua própria cidadania. Desta forma, compartilhamos com Fridman (2000, p. 39) a ideia de que "a multiplicação de informações, conceitos, descobertas e teorias lançou a vida social em variadas direções, com consequências inesperadas e não vistas anteriormente".

Com base nestes aspectos, somente uma abordagem voltada para o conhecimento linguístico e para o desenvolvimento de destrezas como a leitura, a escrita, a fala e a compreensão auditiva não abarcaria as demandas sociais nas quais os alunos estão envolvidos. A fim de executarmos uma análise mais completa, traçaremos um diálogo entre a proposta de Cunningsworth (1995) e a sugestão abaixo explicitada, formulando, assim, a nossa proposta de análise do livro didático Zip From Zog 5A.

Ao enfatizar o trabalho com conteúdos que abordem o cotidiano dos alunos, o material didático do Programa Acelera Brasil dialoga com uma teoria de aprendizagem de base sociointeracional, já que "o aprendizado humano pressupõe uma natureza social específica e um processo através do qual as crianças penetram na vida intelectual daquelas que as cercam" (VYGOTSKY, 1991, p. 59).

Como exemplo de conteúdos socialmente relevantes para os alunos, podemos citar os Temas Transversais propostos pelos PCN (1997). Além de focar nos eixos temáticos, o material didático, com intuito de realizar os objetivos de uma aprendizagem sociointeracional, deve trazer para a sala de aula as práticas sociais nas quais os alunos se engajam diariamente. Chegamos, assim, à concepção bakhtiniana de gêneros do discurso: "tipos relativamente estáveis de enunciados" (BAKHTIN, 1997, p. 280), orais e escritos, que emanam das diversas atividades sociais das quais fazemos parte.

\footnotetext{
${ }^{2}$ Grifos do autor e tradução minha.
} 
Ao admitirmos que gêneros não ocorrem em um vácuo social, é necessário que levemos em conta os contextos em que os mesmos são produzidos, distribuídos e consumidos. Deste modo, Bakhtin (1997) aponta para a importância do estudo da natureza do enunciado, momento em que devemos apontar para os três elementos constitutivos dos gêneros: o tema, a forma composicional e o estilo. O primeiro trata da realidade em que se dá o gênero. Já o segundo aspecto refere-se aos modos de organização ou estruturação do enunciado. E o terceiro está atrelado às escolhas gramaticais e lexicais feitas durante a enunciação.

Dialogando com Bakhtin (1997), ao compreender "a atividade humana concebida como prática social situada" (TILIO \& ROCHA, 2009, p. 303), Halliday \& Hasan (1989) nos apontam três elementos, na verdade metafunções, que permeiam a linguagem e que são fundamentais para o estudo da mesma: a ideacional, a interpessoal e a textual. De forma sucinta, a metafunção ideacional se ocupa da natureza da ação social que está acontecendo e na qual os participantes estão engajados. A metafunção interpessoal referese às interações entre os participantes, seus status, papéis e as relações entre os mesmos. Já a metafunção textual dá conta de como a linguagem organiza a realidade social da qual emerge.

Correlacionando as concepções de Bakhtin (1997) e Halliday \& Hasan (1989), chegamos à aplicação de uma teorização de linguagem do livro didático, com base em Tilio \& Rocha (2009), a fim de complementar a análise sugerida por Cunningsworth (1995):

\section{Teorização de linguagem do livro didático com base em} Tílio \& Rocha (2009)

Ideacional-temática: aborda os eixos temáticos presentes no livro didático;

Interpessoal-composicional: estabelece as relações sociais e de poder entre os envolvidos na prática discursiva; e

Textual-estilística: organiza as escolhas linguísticas feitas ao longo do livro didático. 
Na próxima seção deste artigo iremos nos concentrar na análise propriamente dita, assim como também exploraremos o nosso objeto de estudo, o livro didático Zip From $\operatorname{Zog} 5 A$.

\section{ANALISANDO A ADEQUAÇÃO DO LIVRO DIDÁTICO ZIP FROM ZOG 5A}

O livro didático a ser analisado faz parte da coleção Zip From Zog, material utilizado nas aulas de Inglês dos alunos integrantes do Programa Rio Criança Global (PRCG). A série didática possui este nome em virtude do personagem Zip. Trata-se de um extraterrestre que veio do planeta Zog com o intuito de ajudar as crianças do PRCG a aprender Inglês. A série foi desenvolvida para os alunos do primeiro segmento do Ensino Fundamental, ou seja, do $1^{\circ}$ ao $5^{\circ}$ ano, e por isso o material é composto pelos livros $1 \mathrm{~A}$ ao $5 \mathrm{~A}$ e $1 \mathrm{~B}$ ao $5 \mathrm{~B}$, onde $\mathrm{A}$ é para o primeiro semestre e $\mathrm{B}$ para o segundo.

O material em questão foi desenvolvido pela editora LF Educacional, especializada no desenvolvimento de materiais didáticos para o setor público, da Educação Infantil ao Ensino Médio, e integrante da Learning Factory, editora responsável pelo desenvolvimento e comercialização do material didático da SBCI.

O livro didático Zip From Zog 5 A é composto pelo Livro do Aluno e pelo Play \& Learn. O Livro do Aluno, objeto de nosso estudo e material mais utilizado em sala de aula, contém quatro unidades, sendo cada uma delas formadas por quatro lições, desdobradas em duas páginas. Já o Play \& Learn refere-se a um material complementar constituído de atividades digitais e tarefas impressas, a serem utilizadas em conjunto com um CD-ROM. Devido à abrangência deste trabalho, iremos concentrar a nossa análise na Unidade 1 do Livro do Aluno, já que a mesma é responsável por apresentar o contexto em que os dois volumes do $5^{\circ}$ ano (5A e 5B) são situados.

De acordo com o Manual do Professor, "a série promove o ensino da língua inglesa de forma lúdica e objetiva, priorizando a produção oral em atividades apropriadas à faixa etária que se destina. A linguagem escrita é introduzida a partir do terceiro volume de forma leve e gradual" (p. IV). Como podemos observar, o livro propõe se adequar ao nível escolar dos alunos e, paralelamente, aos objetivos do PRCG ao focar a produção oral da língua alvo.

Ainda com base no Manual, 
Zip From Zog também incorpora temas transversais em suas unidades, como ética, saúde e meio ambiente, pois como qualquer outra disciplina dentro do contexto escolar, o inglês deve levar os alunos a pensar, entender e questionar a realidade sócio-cultural à sua volta. Zip From Zog procura trazer estas questões através de situações simples do dia a dia do aluno (p. IV).

É possível percebemos aqui um diálogo com os PCNs (1997), à medida que o livro didático se preocupa com questões que perpassam a vida dos alunos, como as que são trazidas pelos Temas Transversais. Temos também uma menção às dimensões interpessoal-composicional e ideacional-temática da linguagem, respectivamente, no sentido de que o livro entende o ensino de Inglês como uma forma de dar voz aos alunos, oportunizando a formação crítica dos mesmos, a partir de eixos temáticos relevantes ao cotidiano dos discentes.

Em relação aos objetivos pedagógicos, de forma resumida, o livro diz pretender “capacitar o aluno a usar o vocabulário e as estruturas básicas da língua inglesa de forma comunicativa, (...), com foco especial na produção oral", "sensibilizar o aluno para os sons da língua inglesa" e "levar o aluno a compreender a importância do aprendizado da língua inglesa como uma ferramenta fundamental para o acesso à informação no século XXI e para inserção dele no mundo globalizado" (Manual do Professor, p. IV). Nesta seção do Manual, encontramos uma grande semelhança com as propostas de Cunningsworth (1995) no que diz respeito ao uso da língua em situações reais de comunicação e ao desenvolvimento das quatro habilidades. O material também demonstra estar atento ao momento contemporâneo em que os alunos estão inseridos, reconhecendo o papel que a Língua Inglesa possui nesse cenário.

A partir de agora, veremos como estas concepções se materializam na Unidade 1, cujo tema é Things we wear (Coisas que usamos), conforme nos mostra a Figura 1. Na lição 1, os alunos são apresentados à turma que irá viajar para o planeta Zog com o objetivo de realizar um intercâmbio. A partir deste ponto, os volumes destinados ao $5^{\circ}$ ano são ambientados no período em que esta turma está em Zog. A princípio, temos uma preocupação com a dimensão ideacional-temática. Entretanto, ao nos depararmos com a segunda página da lição (Figura 2), notamos que todo o aparato contextual resume-se apenas em um pano de fundo para que a dimensão textual-estilística ganhe destaque através de atividades que focalizam somente a estrutura da língua. Em nenhum momento o assunto "intercâmbio" é problematizado no livro didático. 


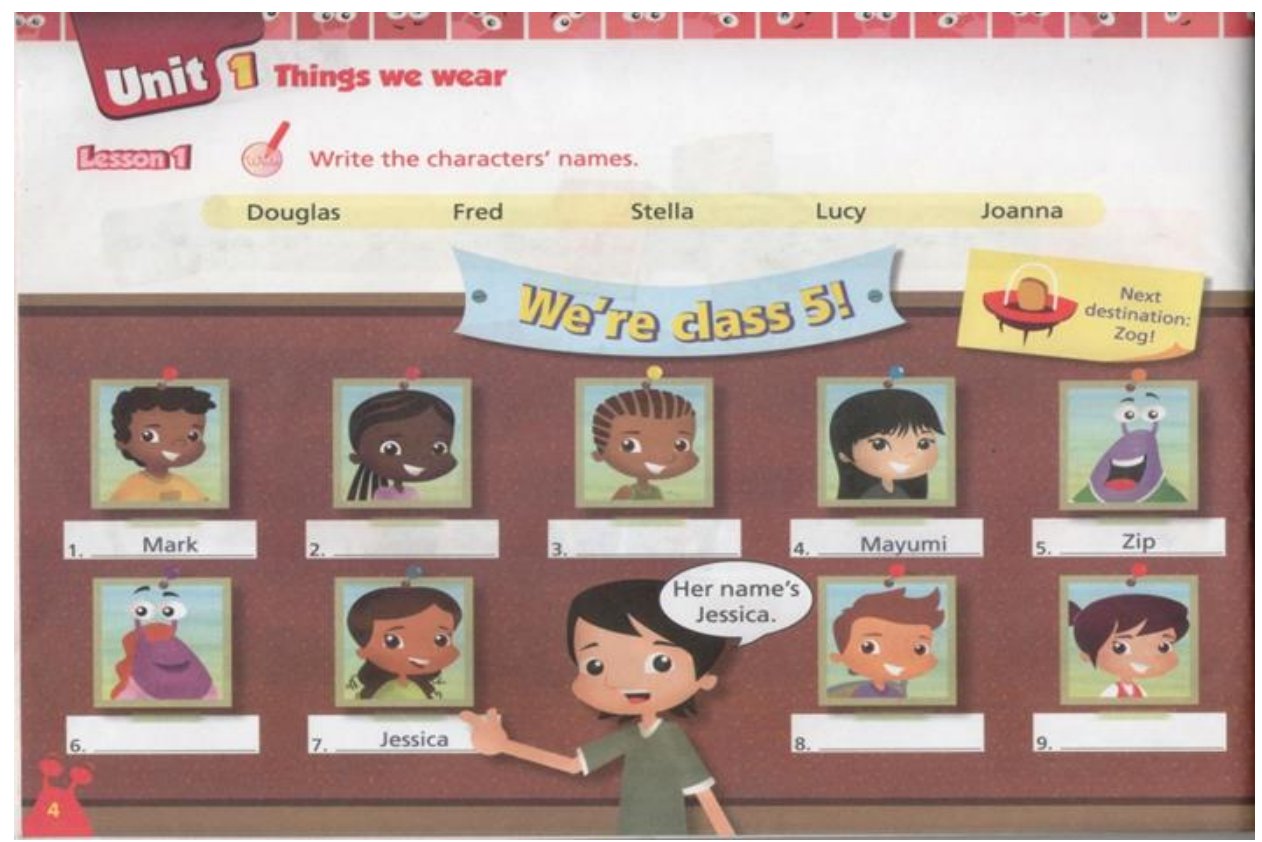

Figura 1

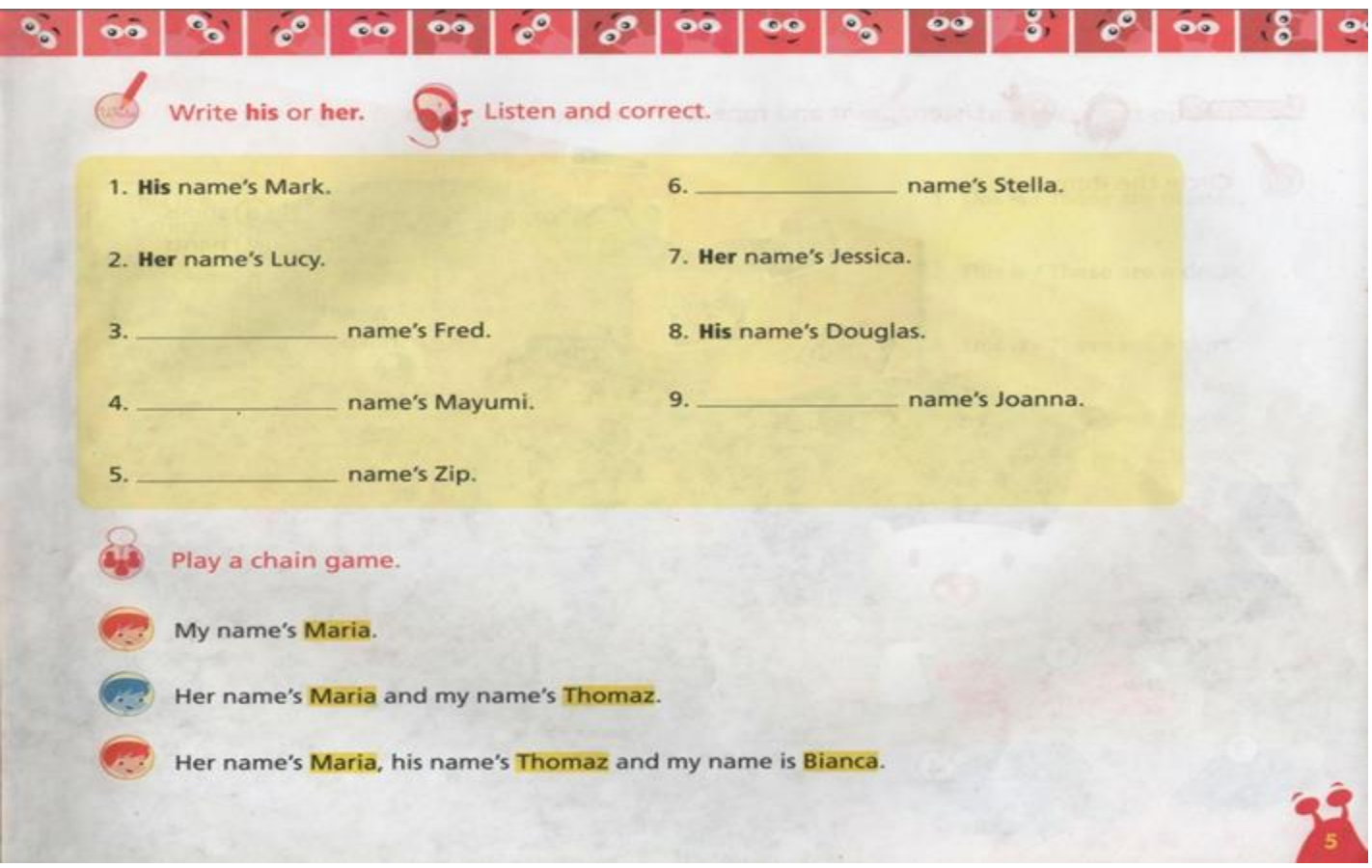

Figura 2

Partindo para a segunda lição (Figuras 3 e 4), temos uma das personagens do livro em seu quarto, arrumando as malas para a viagem. Assim como na primeira lição, o contexto, que a princípio seria trabalhado de forma relevante para os alunos, é trabalhado somente como uma forma de enquadrar os conteúdos léxico-gramaticais da unidade em 
questão.

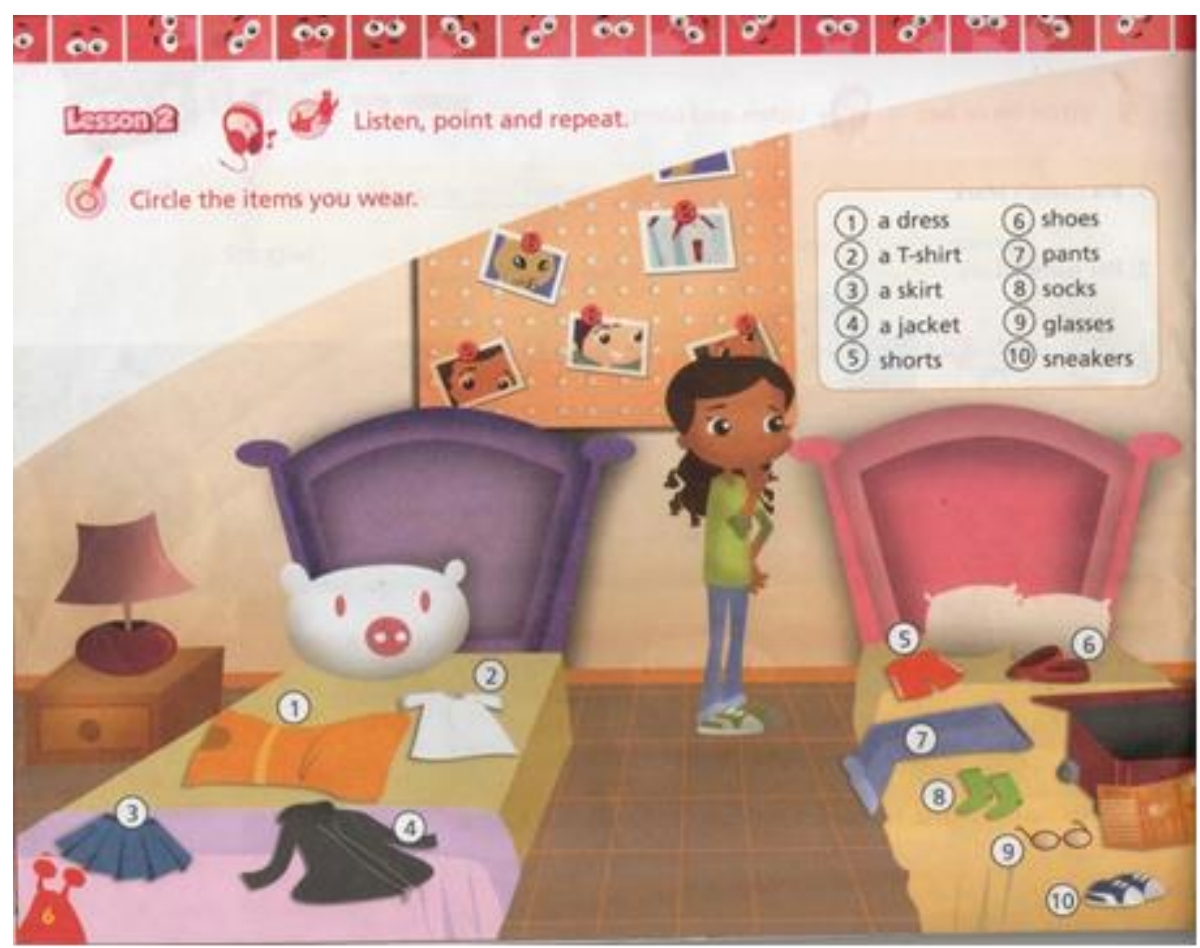

Figura 3

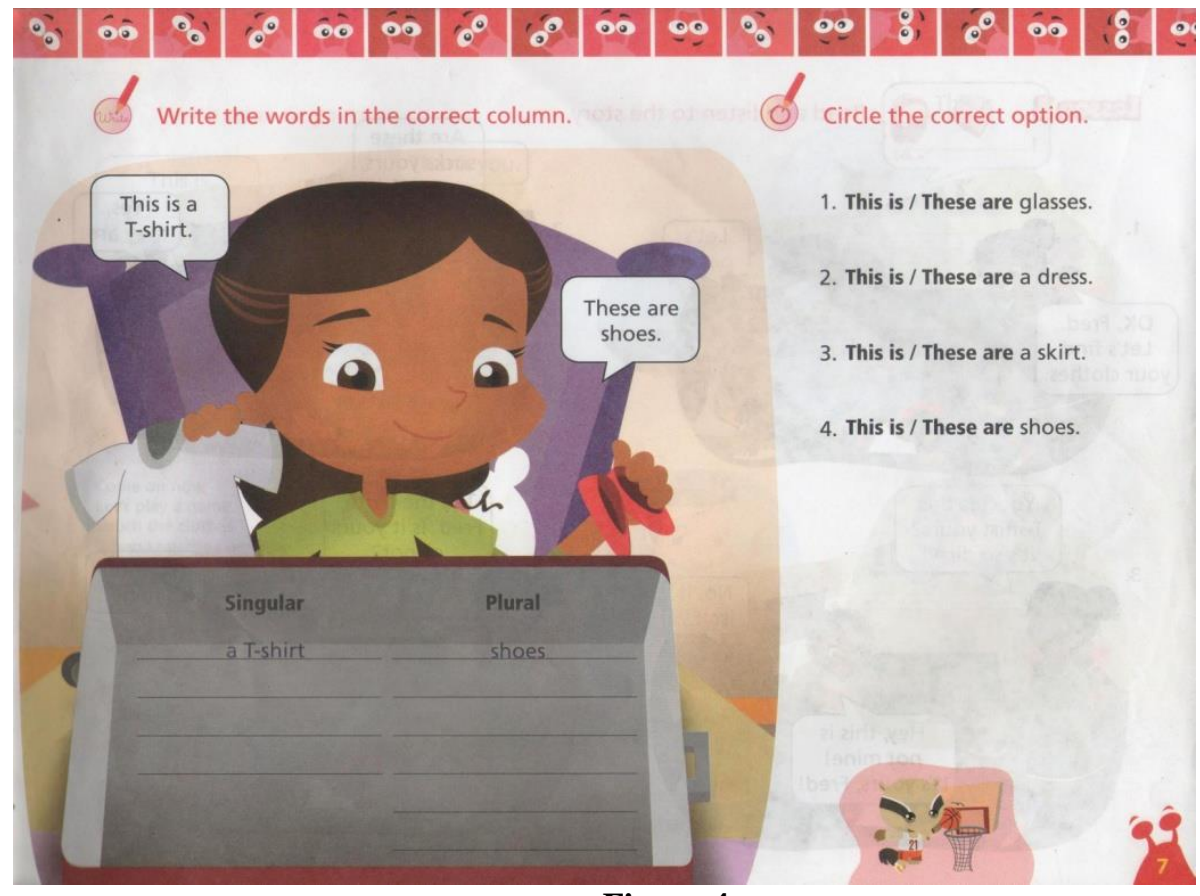

Figura 4

Na lição 3 (Figuras 5 e 6) temos claramente uma oportunidade de abordagem dos Temas Transversais. Trata-se de uma estória envolvendo o personagem Fred e o dilema de contar ou não a 
verdade para a sua mãe. Entretanto, na próxima página, novamente, o contexto é utilizado apenas para apresentar conteúdos estruturais do idioma-alvo, que no caso desta lição, são os pronomes possessivos. Há também o emprego de uma canção, entretanto, não se trata de um material autêntico, uma vez que o mesmo foi elaborado exclusivamente para que os alunos leiam a letra e marquem a figura que melhor representa a descrição presente na canção. Feito isso, os discentes são instruídos a ouvir e cantar a canção.

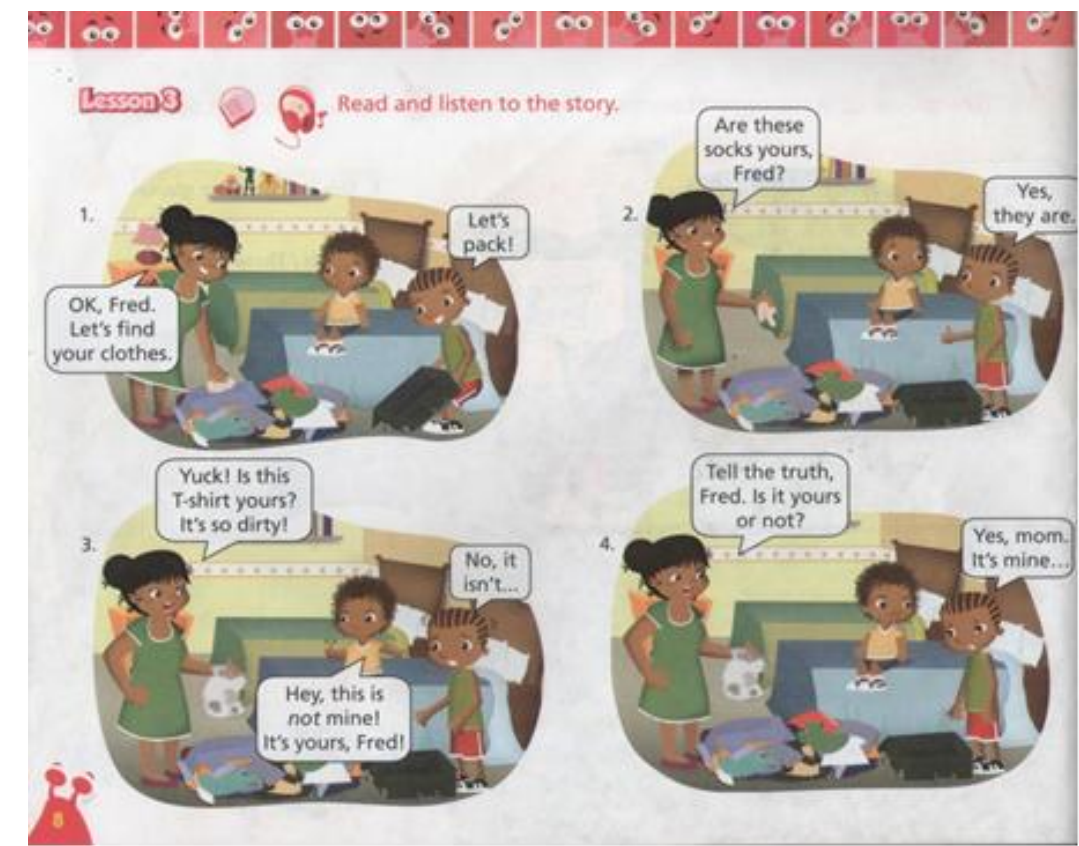

Figura 5

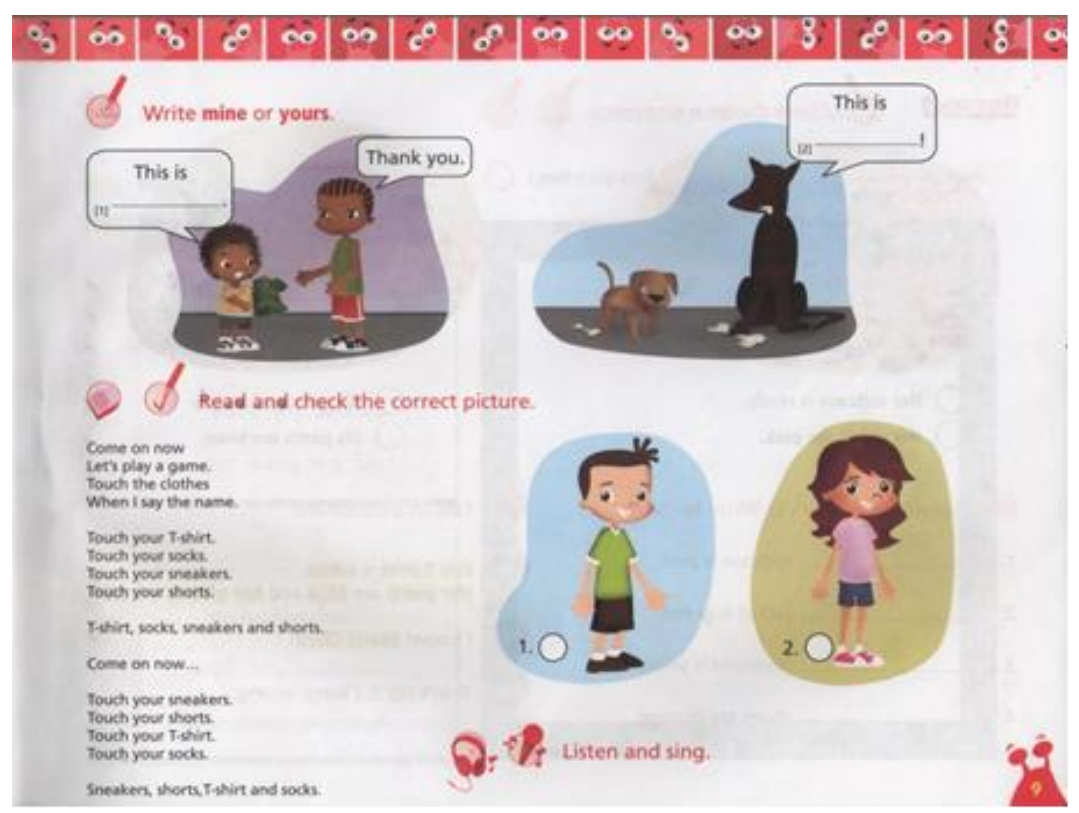

Figura 6 
Por fim, chegamos à lição 4 (Figuras 7 e 8). Desta vez, temos a figura de dois personagens em seus respectivos quartos, Mayumi e Mark. Aqui, também, a dimensão ideacional não é concebida em práticas discursivas, e sim, como situações que ocorrem em um vácuo social, além de fornecer visões generalizantes e estereotipadas sobre as representações do quarto de uma menina e de um menino. Ao final da lição, os alunos são apresentados à duas "listas de afazeres". Assim como na lição 3, também temos a tentativa de se trabalhar com gêneros textuais. Entretanto, nos deparamos com o mesmo aspecto: a falta de autenticidade. Neste sentido, as "listas de afazeres" não são apresentadas com o propósito comunicativo para o qual foram construídas socialmente, mas sim, como uma atividade na qual os alunos devem identificar os autores dos textos, como podemos ver através da Figura 8.

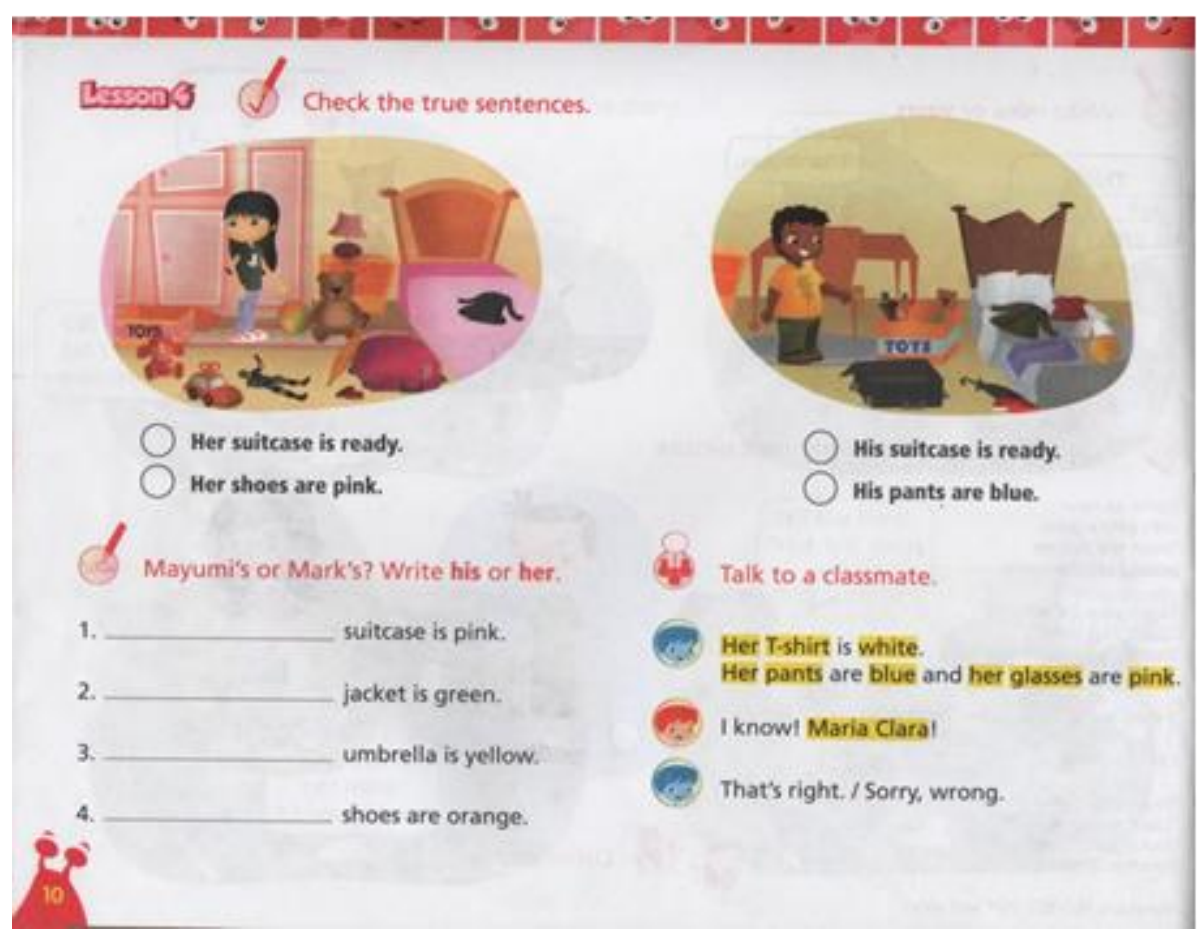

Figura 7 


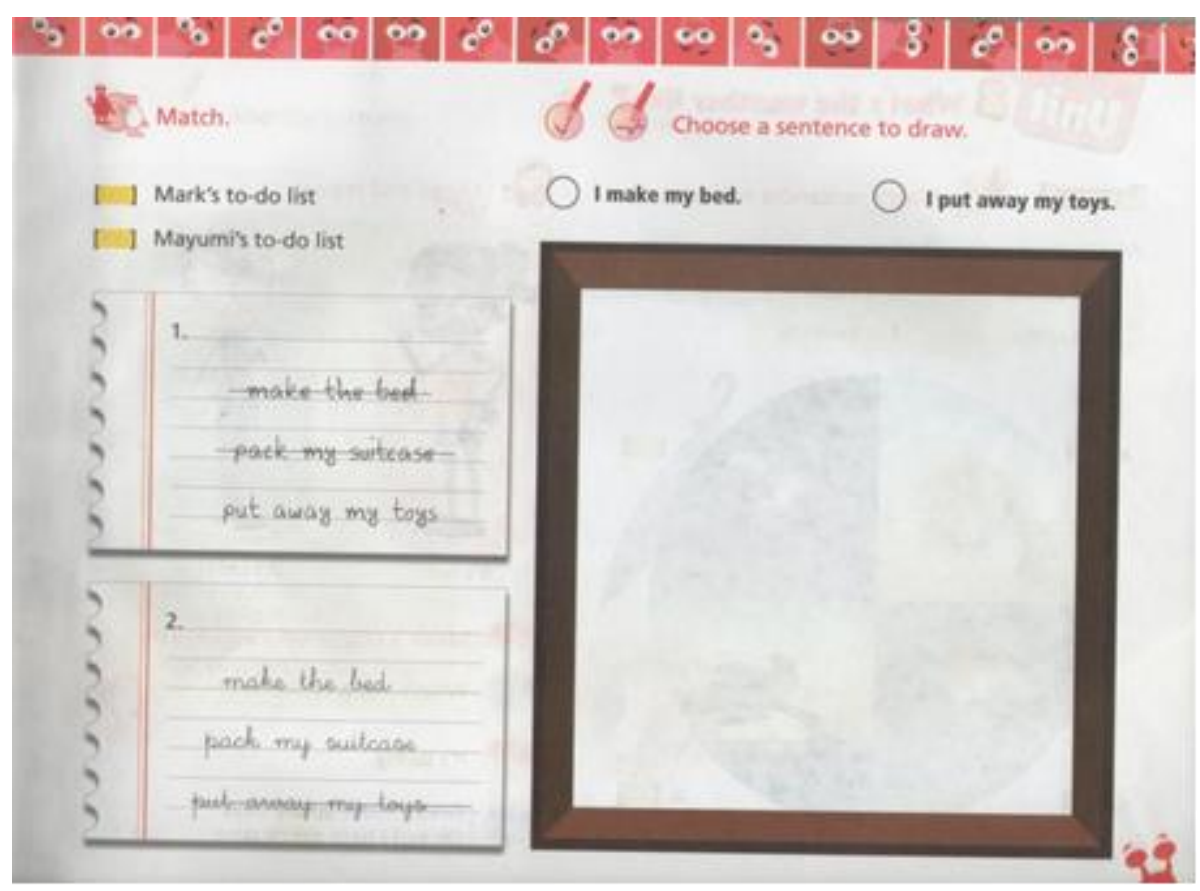

Figura 8

No decorrer da Unidade 1, é notável que o entendimento de tema por parte das autoras do livro difere totalmente da concepção que baseia este artigo, ou seja, da visão do "uso da linguagem em situações e contextos específicos, em um determinado momento sócio-histórico" (TILIO \& ROCHA, 2009, p. 307). Sendo assim, o tema, na concepção das autoras, trata-se do nome dado à unidade, um termo guarda-chuva utilizado para abarcar os conteúdos léxico-gramaticais. E como a unidade privilegia um trabalho estrutural, a dimensão textual-estilística ganha maior relevância, em detrimento das demais. Uma vez que não há tema, não há dimensão ideacional-temática, e por consequência, a dimensão interpessoal-composicional também é prejudicada. Ao contrário do que encontramos no Manual do Professor, os alunos não são levados a pensar, entender ou questionar a realidade à sua volta. Instruções como "write, play, listen, point, repeat, circle, read, check, talk, match, choose and draw" (escreva, jogue, escute, aponte, repita, circule, leia, marque, fale, relacione, escolha e desenhe) não empoderam os alunos, apenas os sujeitam aos comandos do livro didáticos.

\section{CONSIDERAÇÕES FINAIS}

Não pretendemos com este artigo estabelecer as características de um livro didático 
perfeito. Primeiramente, porque não acreditamos que o mesmo exista. Cabe ao professor adequar o material às realidades e necessidades dos seus alunos. Em segundo lugar, isso não significa que não possamos esperar pelo melhor, tanto para os alunos, quanto para professores.

Retomando a nossa problematização "Em que aspectos o livro didático Zip From Zog se adequa ao Programa Acelera Brasil?”, podemos dizer, com base na análise da Unidade 1 e a partir da teorização de linguagem do livro didático presente em Tilio \& Rocha (2009), que a dimensão textual-estilística é privilegiada, em detrimento das dimensões ideacional-temática e interpessoal-composicional. Com isso, as atividades presentes na unidade aqui analisada se distanciam das propostas de uso de linguagem e de ensino-aprendizagem defendidas pela fundamentação teórica presente neste trabalho.

Cabe ressaltarmos que a teorização aqui apresentada não se configura como verdade absoluta, e sim, como uma orientação que possa nortear a análise, e, porque não, a elaboração de matérias didáticos para o ensino de Língua Estrangeira, no nosso caso, de livros didáticos para o ensino de Inglês.

\section{REFERÊNCIAS}

BAKHTIN, Mikhail. Estética da Criação Verbal. 2. ed. São Paulo: Martins Fontes, 1997.

BRASIL. Ministério da Educação, Secretaria de Educação Fundamental. Parâmetros curriculares nacionais : introdução aos parâmetros curriculares nacionais. Brasília, 1997. Disponível em < http://portal.mec.gov.br/seb/arquivos/pdf/livro01.pdf >. Acesso em 14 jul. 2013.

BRASIL. Ministério da educação, Secretaria de Educação Fundamental. Parâmetros curriculares nacionais : apresentação dos temas transversais, ética. Brasília, 1997. Disponível em http://portal.mec.gov.br/seb/arquivos/pdf/livro081.pdf. Acesso em 14 jul. 2013.

CUNNINGSWORTH, Alan. Choosing your coursebook. Oxford: Macmillan, 1995.

FRIDMAN, Luis Carlos. Vertigens pós-modernas: configurações institucionais contemporâneas. 1. ed. Rio de Janeiro: Relume Dumará, 2000.

HALLIDAY, M. A. K.; HASAN, Ruqaiya. Language, context and text: aspects of language in a social- semiotic perspective. 2. ed. Oxford: Oxford University Press, 
1989.

LALLI, Viviane Senna. O Programa Acelera Brasil. Em Aberto, v. 17, p. 145-148, 2000. Disponível em http://www.emaberto.inep.gov.br/index.php/emaberto/index. Acesso em 14 jul. 2013.

LF EDUCACIONAL. Disponível em http://www.lfeducacional.com.br/empresa/quemsomos. Acessado em 21 out. 2012.

PARRADO, Carla; SANTOS, Simone Portes. Zip from Zog, 5A: livro do aluno. 1. ed. Rio de Janeiro: Learning Factory, 2012.

PARRADO, Carla; SANTOS, Simone Portes. Zip from Zog, 5A: manual do professor. 1. ed. Rio de Janeiro: Learning Factory, 2012.

PROGRAMA RIO CRIANÇA GLOBAL. Disponível em http://www.rio.rj.gov.br/web/sme/exibeconteudo?article-id=1100300. Acessado em 21 out 2012.

TÍLIO, Rogério; ROCHA, Cláudia Hilsdorf. As dimensões da linguagem em livros didáticos de Inglês para o Ensino Fundamental I. Trabalhos em Linguística Aplicada, v. 48, p. 295-315, 2009. Disponível em http://www.iel.unicamp.br/revista/index.php/tla/. Acesso em: 14 jul. 2013.

VIGIA-DIAS, Laura; SILVA, Maria Aparecida C.M. Borges da. Autenticidade: em busca de novos caminhos. Intercâmbio, v. VII, p. 57-68, 1998. Disponível em <http://www. revistas.pucsp.br/index.php/intercambio/article/download/4002/2650>. Acesso em 02 set. 2013.

VYGOTSKY, L. S. A Formação Social da Mente. 4. ed. São Paulo: Martins Fontes, 1997.

\section{A AUTORA}

Patrícia Helena da Silva Costa, mestranda, UFRJ

E-mail: patriciahscosta@gmail.com 